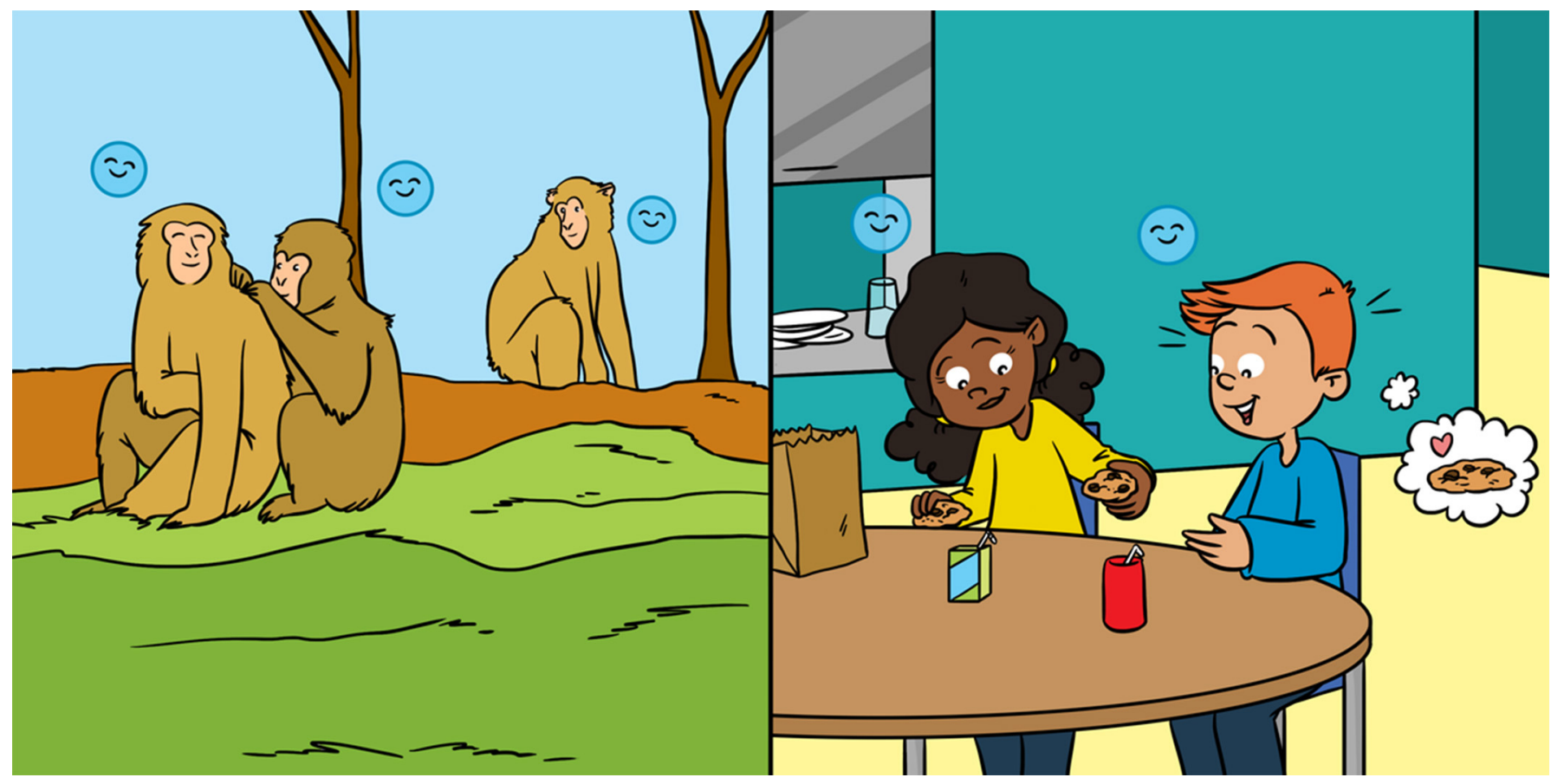

\title{
GOOD VIBES: WHAT HAPPENS WHEN MONKEYS ARE NICE TO EACH OTHER?
}

\section{Stuart Semple *}

Department of Life Sciences, Centre for Research in Evolutionary, Social and Interdisciplinary Anthropology, University of Roehampton, London, United Kingdom

YOUNG REVIEWER:

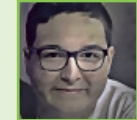

MICHAEL

AGE: 13
Humans belong to a group of animals known as primates. This group includes the lemurs, monkeys, and apes. Scientists have studied the behavior of primates for many years, and one reason for doing this is to find out how similar-or not-primates are to us. This article will tell you about research we have carried out into the social behavior of a monkey known as the Barbary macaque. We looked at a special behavior, grooming, where one animal does a favor to another by cleaning its fur, removing dirt, ticks, and fleas. We discovered that doing grooming makes monkeys feel relaxed, and that even observing others groom has the same effect. These findings suggest that for monkeys, being nice-or just watching others being nice-makes them feel good. This is also true for humans, so our lives and those of the other primates are more similar than we previously thought. 
Figure 1

Examples of primates-a lemur, a monkey, and a great ape.

\section{PRIMATES}

A group of animals that include the lemurs, monkeys, and apes (including humans); the primates are part of a larger group called the mammals.

\section{GROOMING}

Picking through the fur of another animal, not just to clean away dirt and parasites but also to gain favors later.

\section{BETA ENDORPHINS}

Chemicals in the body which have the effect of making you feel good (the great feeling you get after doing exercise is due to these).

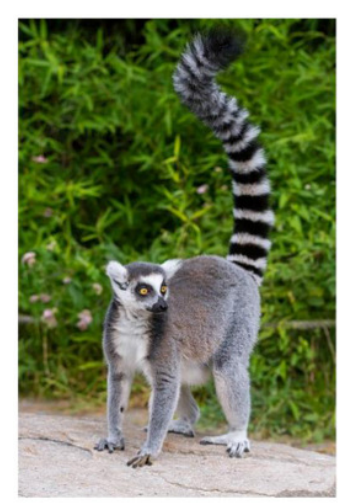

Ring tailed lemur (picture by Matthias Appel, from Intps: en. wikipedia.org/wiki/Ring. tailed_lemur

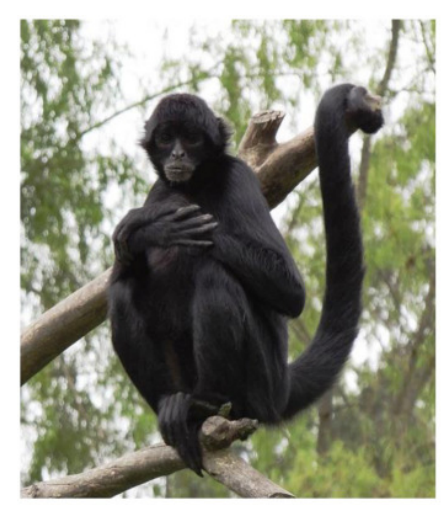

Black-headed spider monkey (picture by Petruss, from ittps://en. wikipedia.org/wiki/Spider monkey

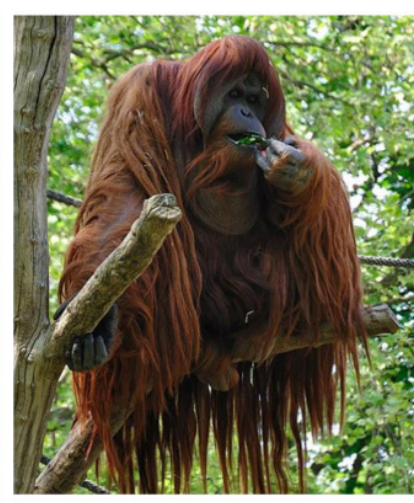

Orangutan
(picture by David Arvidsson, from https://en. wikipedia. org/wiki/Orangutan

Figure 1

\section{STRESS AND GROOMING IN PRIMATES}

The primates are a group of animals that includes the apes, the monkeys, and the lemurs (Figure 1). Humans are primates-we are one of the great apes, along with chimpanzees, bonobos, gorillas, and orangutans. Scientists have learned a lot about what makes us human by studying the behavior of the other primate species. In particular, studies of our primate relatives have helped us to understand the importance of being nice to others.

Our work in this area has focused on the Barbary macaque, a monkey species that, in the wild, lives in the mountains of Morocco and Algeria in northern Africa. There is also an introduced population on the Rock of Gibraltar, in the Iberian Peninsula (Europe). We have looked specifically at a behavior known as grooming. Grooming involves one animal carefully picking through and cleaning the fur of another group member, and is a very common behavior among social primates [1]. It was originally thought that the purpose of grooming was solely to remove dirt, ticks, and other parasites from the fur, but it has become clear that there is much more to it than that. Animals being groomed benefit not only from the cleaning service they receive but also because being groomed is really relaxing and makes them feel good [2]!

There is evidence from several different kinds of monkeys that being groomed lowers heart rate [3], reduces the levels of stress-related hormones [4], and leads to the release of feel-good chemicals known as beta endorphins [5]. All these relaxing effects mean that being groomed is like receiving a monkey massage (Figure 2). Because of the pleasure monkeys feel when they are groomed, this behavior appears to be a type of social currency that can be traded by monkeys for future benefits. For example, grooming can be traded for support in fights-if one monkey grooms another and the one that did the grooming later gets involved in a fight, the one that received the grooming is more 
Figure 2

Two adult female Barbary macaques involved in a grooming session.

\section{GLUCOCORTICOIDS}

Chemicals released in the body when something stressful happens.

\section{METABOLITES}

When your body breaks things down (this is called metabolism), what is left are the metabolites.

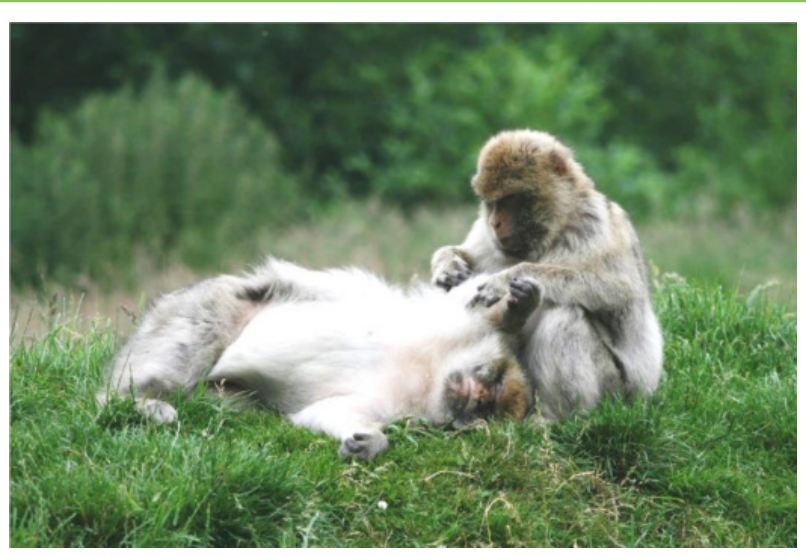

Figure 2

likely to come to their aid [6]. This is the typical case of "if you scratch my back, I will scratch yours."

\section{GROOMING, GOOD TO GIVE AS WELL AS TO RECEIVE?}

We decided to look at grooming in a new way-to find out if giving grooming is also relaxing [7]. We worked with the Barbary macaque population in Gibraltar and wanted to measure the stress levels of animals that we saw grooming. The goal was to know if those Barbary macaques that did more grooming were more relaxed as a result. To do this, we used methods that did not involve capturing the monkeys, for example to collect blood samples, as doing so would of course cause them to be stressed.

So, what we did was collect poo (or as scientists say "fecal samples"). While this may seem a strange thing to do, fecal samples can give an insight into what monkeys are feeling. When a monkey feels stressed, its body releases hormones called glucocorticoids. Once the glucocorticoids have served their purpose, they are broken down by the liver and some of what is left-these are called metabolites-pass out in the feces. By collecting fecal samples and then using some neat chemical processes to measure the concentration of stress hormones, scientists can know which monkeys are stressed, and which are chilled out.

In total, we collected between three and six samples from each of 12 adult female monkeys. We also measured how much time each animal spent being groomed and grooming others. Male monkeys groom too, but a lot less than females, so we decided not to study males. When the data on grooming and glucocorticoid metabolite levels were analyzed, something really surprising was found: the quantity of glucocorticoid metabolite was not related to the time spent being groomed but was related to the time spent grooming. This means that monkeys that did more grooming had lower stress. For this species, it seems it is better 
POSITIVE VISUAL

\section{CONTAGION}

When you see someone being nice, that makes you be nice to others.

\section{DISPLACEMENT}

BEHAVIOR

\section{A group of}

behaviors-like scratching, touching your face or hair-that in humans we call fidgeting to give than to receive! Another important finding was that the number of grooming partners was also important. We found that animals that gave grooming to a larger number of others had even lower levels of these metabolites. In other others, they were less stressed.

So what might be going on here? We think that by doing a lot of grooming-and spreading grooming among lots of their group mates-Barbary macaques build up a large network of potential supporters. This means that when one macaque gets into a stressful situation, it can count on being backed up by those friends it has groomed before. This means that, on average, Barbary macaques that built up a group of potential allies are more relaxed than animals that have not.

\section{FRIENDLY BEHAVIOR IS CONTAGIOUS}

We also wanted to know what happens to those Barbary macaques that just watched others grooming and being groomed [8]. This idea was inspired by research in humans that showed that seeing others act in a friendly way not only makes people feel good, but also encourages them to pass the good feelings to others. This is known as positive visual contagion and was thought to be unique to humans. Probably, monkeys experience positive visual contagion too.

So, we decided to compare the behavior of female macaques in two situations: after they had and after they had not watched others grooming. We measured a particular type of behavior known as displacement behavior. Displacement behavior includes scratching and self-grooming-the sort of thing that called fidgeting in humans. We knew that displacement behavior provides a measure of primates' emotions: when animals are in a stressful situation, they show more displacement behavior, while a reduction in displacement behavior indicates that animals are relaxed.

The results of the study revealed that macaques showed much less displacement behavior after watching others groom. It seems that it is relaxing to watch others relaxing! Also, animals that watched others groom were also more likely to later groom others. So, friendly behavior does indeed appear to be contagious for these monkeys.

\section{HUMANS, BE NICE TO EACH OTHER}

Humans do not openly groom each other on the street or at work to reduce stress, although you could see a trip to the hair salon or going for a massage as forms of grooming. While we certainly do not spend as much time grooming as monkeys do, these two studies of Barbary macaques could help us understand why, with a few exceptions, we 
tend to be a friendly species. During our evolutionary history, making others feel good may have been rewarding in itself, and even just watching others being nice to each other may have led to positive feelings. This is likely to have been very important throughout human evolution, maintaining friendliness and a desire to help others in the societies in which our ancestors lived.

\section{REFERENCES}

1. Dunbar, R. I. M. 1991. Functional significance of social grooming in primates. Folia Primatol. 57:121-31. doi: 10.1159/000156574

2. Russell, Y. I., and Phelps, S. 2013. How do you measure pleasure? A discussion about intrinsic costs and benefits in primate allogrooming. Biol. Philos. 28:1005-20. doi: 10.1007/s10539-013-9372-4

3. Aureli, F., Preston, S. D., and de Waal, F. B. 1999. Heart rate responses to social interactions in free-moving rhesus macaques (Macaca mulatta): a pilot study. J. Comp. Psychol. 113:59-65. doi: 10.1037/0735-7036.113.1.59

4. Gust, D. A., Gordon, T. P., Hambright, M. K., and Wilson, M. E. 1993. Relationship between social factors and pituitary: adrenocortical activity in female rhesus monkeys (Macaca mulatta). Horm. Behav. 27:318-31. doi: 10.1006/ hbeh.1993.1024

5. Keverne, E. B., Martensz, N. D., and Tuite, B. 1989. Betaendorphin concentrations in cerebrospinal fluid of monkeys are influenced by grooming relationships. Psychoneuroendocrinology 14:155-61. doi: 10.1016/0306-4530(89)90065-6

6. Carne, C., Wiper, S., and Semple, S. 2011. The reciprocation and interchange of grooming, agonistic support, feeding tolerance and aggression in semi-free-ranging Barbary macaques. Am. J. Primatol. 73:1-7. doi: 10.1002/ ajp.20979

7. Shutt, K., MacLarnon, A., Heistermann, M., and Semple, S. 2007. Grooming in Barbary macaques: better to give than receive? Biol. Lett. 3:231-3. doi: 10.1098/ rsbl.2007.0052

8. Berthier, J., and Semple, S. 2018. Observing grooming promotes affiliation in Barbary macaques. Proc. Roy. Soc. Lond. B 285:20181964. doi: 10.1098/ rspb.2018.1964

SUBMITTED: 23 June 2020; ACCEPTED: 06 April 2021; PUBLISHED ONLINE: 12 May 2021.

EDITED BY: Michele A. Johnson, Trinity University, United States

CITATION: Semple S (2021) Good Vibes: What Happens When Monkeys Are Nice to Each Other? Front. Young Minds 9:575499. doi: 10.3389/frym.2021.575499

CONFLICT OF INTEREST: The author declares that the research was conducted in the absence of any commercial or financial relationships that could be construed as a potential conflict of interest.

COPYRIGHT @ 2021 Semple. This is an open-access article distributed under the terms of the Creative Commons Attribution License (CC BY). The use, distribution 


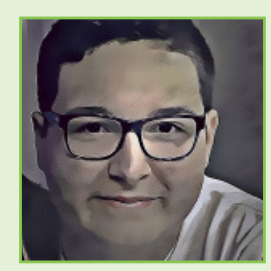

or reproduction in other forums is permitted, provided the original author(s) and the copyright owner(s) are credited and that the original publication in this journal is cited, in accordance with accepted academic practice. No use, distribution or reproduction is permitted which does not comply with these terms.

\section{YOUNG REVIEWER}

\section{MICHAEL, AGE: 13}

I am a video game fanatic, and I also study very hard to keep up with my school work. My favorite topic in school is Biology followed by History. I keep up with the political news and 1 day I aspire to be a doctor, but not sure yet what type of doctor I want to be. I live with five cats and two dogs.

\section{AUTHOR}

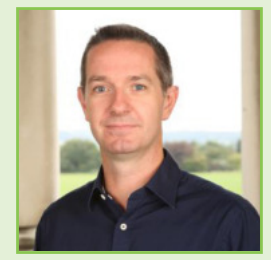

\section{STUART SEMPLE}

I am a Professor of Evolutionary Anthropology at the University of Roehampton in London. I started out in science studying coral reefs, but soon became fascinated with the behavior of monkeys. I have been studying these animals for over 25 years, working with baboons in Kenya, and Barbary macaques in Gibraltar and Morocco. The work I talk about in this piece involved my colleagues, Kat Shutt, Juliette Berthier, and Ann MacLarnon. *s.semple@roehampton.ac.uk 